\title{
CHUÁ, CHUÁ, ÁGUA BOA PRA TOMAR Avaliação higiênico-sanitária da água, bebedouros e manipuladores de alimentos em escola municipal
}

\author{
Hygienic-sanitary evaluation of water, drinking \\ fountains and food handlers in a municipal school.
}

Evaluación higiénico-sanitaria del agua, bebederos y manipuladores de alimentos en una escuela municipal

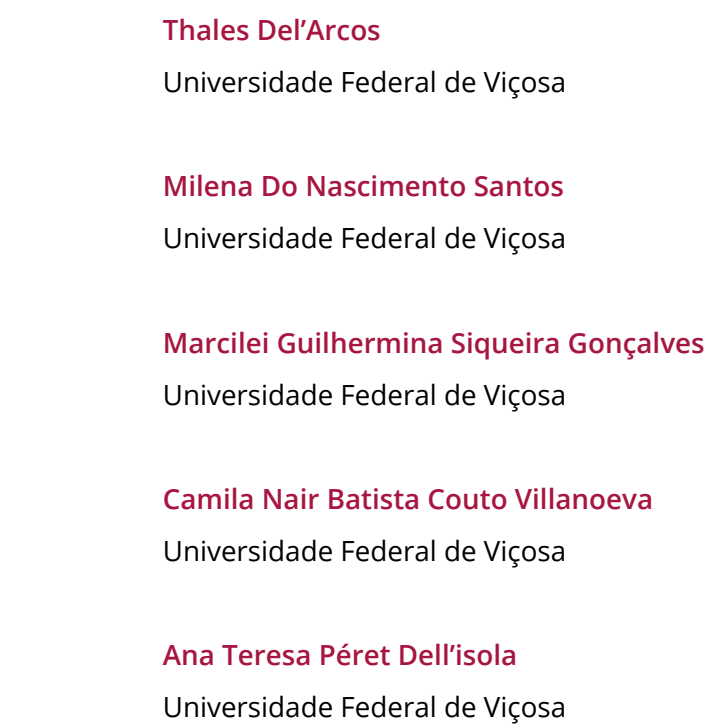

Resumo: Muitas crianças têm a alimentação escolar como principal refeição durante o dia, porém muitas escolas brasileiras não possuem um programa de higienização que visa estabelecer o procedimento operacional pela qual as instituições evitarão as contaminações diretas e cruzadas e bem como preservarão a saú- 
de dos alunos. Portanto, este trabalho teve como objetivo a avaliação microbiológica da água e das condições higiênico-sanitárias de bebedouros, torneiras e manipuladores de alimentos em escola municipal. As amostras foram coletadas em três repetições e analisadas em triplicata. Os resultados foram avaliados com o auxílio do software SPSS $21.0{ }^{\circledR}$. Realizou-se a pesquisa de coliformes totais e termotolerantes na água e micro-organismos mesófilos nas superfícies. A água das caixas d'água apresentou resultados satisfatórios e está de acordo com a legislação. A qualidade higiênico-sanitária das superfícies e dos manipuladores foram insatisfatórias. Esse cenário pode ser melhorado por meio de treinamentos contínuos e maior sensibilização e engajamento de toda a equipe escolar.

Palavras-chaves: Água. Microbiologia. Higiene. Alimentos. Escola.

2

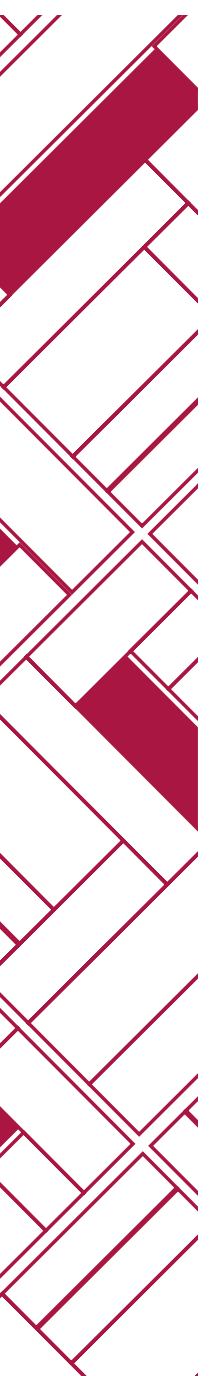

Abstract: Many childrens have school meals as their main meal during the day, but many brazilians schools do not have a hygiene program that aims to establish the routine way in which institutions will avoid direct or cross-contamination and preserve students health. Therefore, this work paper aims at the water microbiological evaluation and hygienic-sanitary conditions of drinking fountains, taps and food handlers in a municipal school. The samples were collected and analyzed in three repetitions and in triplicate. The results were evaluated using the SPSS $21.0{ }^{\circledR}$ software. Analyzes of total coliforms and thermotolerant and swabs of the surface were performed to detect mesophilic microorganism. The tank's water presents satisfactory results and is in accordance with the legislation. But the hygienic-sanitary conditions of the surfaces analyzed presents higher results as the recommended to satisfactory hygienic conditions, including the mugs that children share and that can become a vehicle for disease. This scenario can be improved by 
continuous training and higher sensibilization and school administration engagement.

Key words: Water. Microbiology. Hygienic. Foods. School.

Resumen: Muchos niños tienen la alimentación escolar como su comida principal durante el día, pero muchas escuelas brasileñas no tienen un programa de higiene que tenga como objetivo establecer la forma rutinaria en que las instituciones evitarán la contaminación directa o cruzada y preservarán la salud de los estudiantes. Por lo tanto, este trabajo tuvo como objetivo la evaluación microbiológica del agua y las condiciones higiénico-sanitarias de bebederos, grifos y manipuladores de alimentos en una escuela municipal. Las muestras fueron recolectadas y analizadas en tres repeticiones y por triplicado. Los resultados se evaluaron utilizando el software SPSS $21.0 \circledR$. Se realizaron análisis de coliformes totales y termotolerantes en hisopos de agua y superficie para detectar microorganismos mesofílicos. El agua en los tanques de agua mostró resultados satisfactorios y está de acuerdo con la legislación. La calidad higiénico-sanitaria de las superficies analizadas, por otro lado, mostró resultados superiores a los recomendados para condiciones higiénicas satisfactorias, incluso en relación a las tazas que comparten los niños y que pueden convertirse en un vehículo para enfermedades. Este escenario se puede mejorar a través de la capacitación continua y una mayor conciencia, sensibilidad y participación de la administración escolar.

Palabras clave: Agua. Microbiologia. Higiene. Alimentos. Escuela.

Data de submissão: 25/06/2020

Data de aprovação: 02/12/2020 


\section{Introdução}

O controle da qualidade sanitária da água destinada ao consumo humano é salutar, pois a sua contaminação torna-se um in luente meio de transmissão de doenças de veiculação hídrica (MANCHESTER et al., 2013). A ingestão de alimentos contaminados com micro-organismos, provenientes de água de má qualidade, utilizada em seu preparo, pode tornar-se um problema gravíssimo para aqueles que fazem o consumo e, consequentemente, para os órgãos de saúde pública, uma vez que os gastos com o tratamento de doenças por ingestão de alimentos contaminados são significativos (SOUSA, 2006). Entre os grupos mais expostos ao risco de doenças de veiculação hídrica estão as crianças, pessoas imunossuprimidas e idosos.

Inúmeras crianças têm a alimentação escolar como refeição principal durante o dia, porém diversas escolas brasileiras não possuem um programa de higienização dos reservatórios de água, seja por imprudência, seja por falta de conhecimento ou ausência de investimentos na área. Com isso, esses reservatórios acabam permanecendo por longos períodos sem nenhum tipo de tratamento. Como consequência, quando consumida, a água contaminada com micro-organismos patogênicos, pode provocar diretamente quadros de doenças infecciosas e indiretamente, a contaminação dos alimentos (ROCHA et al; 2010).

Em ambientes educacionais, a preparação da alimentação escolar deve considerar a produção de alimentos seguros. Os principais riscos das contaminações estão associados a fatores como: preparo de um grande número de refeições, que são servidas em condições operacionais impróprias; o longo tempo entre o preparo e a distribuição destas e a insuficiente qualificação dos manipu- 
ladores, o que possibilita maiores chances de exposição dos alimentos a contaminações e de multiplicação microbiana (SILVA et al., 2003). Soma-se a isso, a inexistência do uso de medidas higiêni-co-sanitárias; manipuladores infectados ou com hábitos higiênicos insatisfatórios, além do uso de água não potável (FORTUNA, 2002).

Os bebedouros também são fontes potenciais de contaminação, seja de forma direta através da água contaminada ou indireta a partir do contato com o equipamento, pois são utilizados por muitas pessoas com hábitos de higiene desconhecidos (ARAÚjO et al., 2009). Nas escolas, esses equipamentos são acessados principalmente pelos alunos, sendo que, nos intervalos das aulas, mui-tas crianças utilizam os banheiros e em seguida bebem água nos bebedouros. Algumas vezes, os hábitos higiênicos são ignorados, tornando-se um potencial risco à saúde coletiva (CASTANIA, 2009).

Essas condições comprometem a produção de alimentos seguros e colocam em risco a saúde dos alunos. Portanto, é imprescindível a realização de análises microbiológicas periódicas nos reservatórios de água, saídas de bebedouros e torneiras das cozinhas de escolas e das mãos dos manipuladores de alimentos para avaliação das condições higiênico-sanitárias das

\section{Objetivostituições de ensino.}

Neste sentido, este trabalho objetivou promover a avaliação da qualidade microbiológica e as condições higiênico-sanitárias da água utilizada no preparo da merenda escolar, de bebedouros e das mãos dos manipuladores de alimentos de uma instituição pública de ensino fundamental. 


\section{Metodologia}

\section{Público envolvido}

O projeto de extensão foi realizado em uma escola pública situada na cidade de Florestal, Minas Gerais. Essa instituição atende cerca de 500 alunos e o público alvo escolhido foram os estudantes participantes do Projeto Mais Educação, que desenvolvem atividades em período integral, além de serem de famílias de baixa renda. O projeto abordou também, os funcionários da instituição, como os manipuladores de alimentos/merendeiras, professores e a direção. Todos os participantes assinaram o Termo de Consentimento Livre e Esclarecido (TCLE), em duas vias, ficando uma com o participante e outra com o pesquisador.

\section{Delineamento experimental}

6

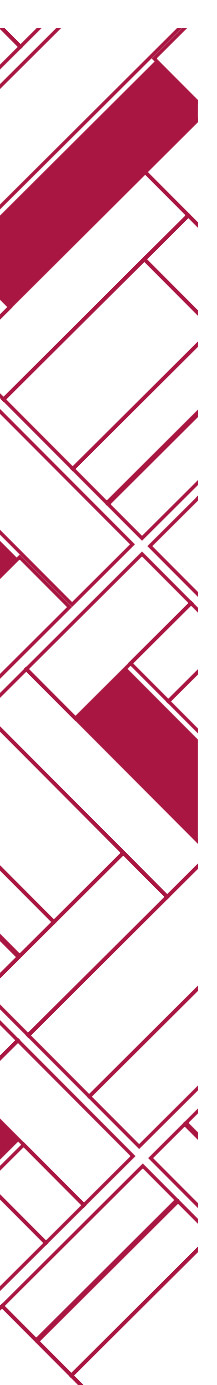
casualizado (DIC), no qual os fatores serão considerados antes do treinamento/conscientização e pós treinamento/conscientização. Realizou-se três repetições constituídas por diferentes semanas de análises, sendo estas realizadas em triplicata. Todos os procedimentos operacionais de análise foram realizados com o auxílio do software SPSS 21.0® (Statistical Package for the Social Sciences).

\section{Análise microbiológica da água}

As análises microbiológicas foram realizadas no Laboratório de Microbiologia da Universidade Federal de Viçosa (UFV) - campus Florestal. A coleta das amostras de água de abastecimento procedeu utilizando frascos de vidro esterilizados, com capacidade de $250 \mathrm{~mL}$.

A análise microbiológica da água da caixa d água foi realizada em dois pontos de abastecimento. O primeiro ponto intitulado 
como caixa superior (CS) é responsável pelo abastecimento de banheiros, bebedouro, sala de coordenação e algumas salas de aula do piso superior da escola. A caixa inferior $(\mathrm{Cl})$ fornece água para a cozinha, bebedouro, banheiros, pia de higienização bucal e de mãos, entre outros.

A água foi coletada da principal torneira da cozinha e das saídas dos bebedouros da instituição de ensino após três minutos de escoamento sendo transportados em recipiente isotérmico, com gelo, até o laboratório e em seguida, foram submetidas às análises microbiológicas.

As amostras de água foram submetidas à pesquisa de coliformes totais e termotolerantes pela técnica do Número Mais Provável (NMP) e Escherichia coli. Os métodos empregados basearam-se na Instrução Normativa $N^{\circ} 62$, de 26 de agosto de 2003, que dispõe sobre os métodos analíticos oficiais para análises microbiológicas para controle de produtos de origem animal e água (BRASIL, 2003). E os resultados obtidos foram comparados com os padrões de potabilidade de água estabelecidos pela Portaria de Consolidação n5 do Ministério da Saúde (BRASIL, 2017).

\section{Avaliação higiênico-sanitária das mãos dos manipuladores}

A condição higiênico-sanitária das mãos dos manipuladores foi realizada pela técnica de swab. Iniciou-se a coleta com swab umedecido em solução salina peptona (SSP) e friccionou-se o algodão três vezes em direção a cada um dos dedos a partir do punho. Em seguida, a partir do punho, friccionou-se novamente o algodão do mesmo swab entre os dedos, retornando novamente ao punho. O swab foi transferido para o tubo contendo $10 \mathrm{~mL}$ de solução tampão fosfato e em seguida realizada a pesquisa de micro-organismos mesofilos aeróbios e facultativos viáveis. Os resultados foram expressos em UFC/mão (BRASIL, 2003; ANDRADE, 2008). 


\section{Avaliação higiênico-sanitária das superfícies dos aparelhos de bebedouro e torneiras}

A condição higiênico-sanitária dos bebedouros e torneiras foi avaliada por swab. A coleta de micro-organismos nas superfícies dos aparelhos foi realizada utilizando-se o swab esterilizado e iniciando-se a coleta com swab umedecido em SSP 0,85\%, friccionando o algodão em movimentos giratórios nos bocais dos bebedouros e após introduziu-o rapidamente no interior do tubo e em seguida realizada a pesquisa de micro-organismos mesofilos aeróbios e facultativos viáveis. Os resultados foram expressos em UFC/superfície (ANDRADE, 2008).

\section{Treinamento teórico-prático sobre condições higiêni- co-sanitárias e boas práticas de fabricação (BPF)}

O treinamento dos funcionários foi baseado na Portaria n³68, de 4 de setembro de 1997, do Ministério da Agricultura, Pecuária e Abastecimento, que regulamenta as condições higiênico-sanitárias e de boas práticas de fabricação (BPF) para estabelecimentos elaboradores/industrializadores de alimentos (BRASIL, 1997). A ação incisiva com os manipuladores de alimentos e/ou funcionários da escola, deu-se por meio de exposições dialogadas, audiovisuais e interativas, de fácil entendimento e com linguagem facilitada.

\section{Questionários de avaliação de conhecimentos}

Com o objetivo de avaliar os conhecimentos prévios das funcionárias em relação as BPF, aplicou-se um questionário estruturado contendo dez questões de múltipla escolha. Também foi aplicado ao final do treinamento teórico-prático a fim de averiguar a efetividade do mesmo além de mensurar o aprendizado absorvido pelas participantes. As perguntas presentes no questionário são apresentadas a seguir no Quadro 1. 


\section{Perguntas}

1) O que são boas práticas de fabricação?

2) $O$ que significa a sigla BPF?

3) $\mathrm{O}$ aluno estava consumindo um bolinho frito e encontrou um fragmento de osso. Marque a opção CORRETA nesta situação.

4) João consumiu uma maionese, que estava deliciosa. Algumas horas depois começou a sentir fortes dores abdominais e teve diarreia. Qual possível contaminante estava no alimento?

5) Na área de produção de uma indústria alimentícia, os perigos químicos podem ocorrer devido $\mathrm{a}(\mathrm{o})$ ?

6) A água boa para ser utilizada na cozinha industrial deve ter?

7) Sobre o processo de higienização, marque a alternativa CORRETA.

8) Sobre a higienização das mãos, marque a alternativa CORRETA.

9) Existem hábitos que devem ser evitados durante a manipulação de alimentos. São eles.

10) Por que os alimentos estragam? Assinale a alternativa INCORRETA.

Quadro 1: Perguntas utilizadas na avaliação de conhecimentos das merendeiras. Fonte: Elaborado pelos autores.

\section{Atividades de conscientização e sensibilização}

Foram elaboradas três cartilhas durante o desenvolvimento do projeto na escola, que foram distribuídas aos responsáveis pela instituição de ensino durante as visitas: uma descreve a importância de se consumir água de qualidade e dentro dos padrões estabelecidos pelo Ministério da Saúde; outra explica o passo a passo para se obter com êxito a correta higienização de uma caixa d'água e a importância de sua manutenção contínua e por fim uma apresentando todos os passos para a correta higienização das mãos. 
Para o incentivo da correta higienização das mãos, realizou-se uma gincana com utilização de tintas guache para chamar a atenção de funcionários e alunos sobre quais são as áreas das mãos que mais são esquecidas durante o processo de higienização além de apresentar técnicas para melhorias desse cenário.

\section{Análise estatística}

As análises estatísticas das amostras de água foram realizadas no software SPSS $21.0 ®$, em nível de significância de 5\%. Os efeitos do treinamento/conscientização sobre a condição higiênico-sanitária foram determinados por meio da análise de variância (ANOVA) e, quando significativos, as médias foram comparadas pelo Teste de Tukey.

\section{Resultados e Discussões}

\section{Análises Microbiológicas}

Os resultados para a pesquisa de coliformes totais e termotolerantes provenientes das três repetições feitas em triplicatas são apresentados respectivamente na Tabela 1.

\begin{tabular}{l|l|l|l|}
\hline $\begin{array}{l}\text { Ponto de } \\
\text { Coleta }\end{array}$ & $\begin{array}{l}\text { Coliformes totais } \\
(\mathrm{NMP} / 100 \mathrm{~mL})\end{array}$ & $\begin{array}{l}\text { Coliformes } \\
\text { termotolerantes } \\
(\mathrm{NMP} / 100 \mathrm{~mL})\end{array}$ & $\begin{array}{l}\text { Padrão } \\
\text { (Portaria de } \\
\text { Consolidação } \\
\left.\mathrm{n}^{\circ} 5, \mathrm{MS}, 2017\right)\end{array}$ \\
\hline $\begin{array}{l}\text { Caixa de água } \\
\text { superior (CS) }\end{array}$ & $<3,0 \pm 0,0$ & $<3,0 \pm 0,0$ & \multirow{2}{*}{ Ausência em 100mL } \\
\hline $\begin{array}{l}\text { Caixa de água } \\
\text { inferior (CI) }\end{array}$ & $<3,0 \pm 0,0$ & $<3,0 \pm 0,0$ & \\
\hline
\end{tabular}

Tabela 1: Resultados das análises microbiológicas da água. Fonte: Elaborado pelos autores. 
Os resultados das amostras de água das torneiras da escola da rede municipal foram negativos para coliformes totais e termotolerantes e estão em conformidade com a Portaria de Consolidação N5, do Ministério da Saúde de 2017 e não diferiram entre si $(p>0,05)$. Resultados semelhantes usando a mesma técnica dos tubos múltiplos foram encontrados em análises de amostras de água de estabelecimentos de ensino da educação infantil da rede pública do Gama, cidade do Distrito Federal, onde nenhuma das amostras analisadas apresentou resultado positivo para coliformes totais e termotolerantes (CRUZ et al., 2009), e também nos estudos realizados por MÜLLER e PARUSSOLO (2014) em escolas municipais de Mamborê, no estado do Paraná, com todas as amostras negativas. Segundo GIRARDI (2012), em um estudo na rede pública de ensino de São Miguel do Oeste, verificaram que $88,0 \%$ das amostras analisadas estavam isentas de coliformes, sendo assim própria para o consumo humano.

Os resultados obtidos no estudo são de extrema importância para a comunidade escolar, visto que os maiores riscos à saúde estão associados ao consumo de água e/ou alimentos contaminados por agentes patogênicos. De acordo com Kosek et al. (2003), cerca de 15 a 20\% das crianças adquirem diarreias nos primeiros anos de vida, em decorrência da presença desses patógenos e/ou de seus metabólitos, nos meios mencionados.

\section{Avaliação higiênico-sanitária das mãos dos manipuladores}

Sabe-se que higienização das mãos é uma das principais medidas para minimizar a quantidade de micro-organismos e assim melhorar a produção de alimentos seguros (RIBEIRO et al., 2000). Neste sentido, as seis colaboradoras (100\%) afirmaram nos questionaram que lavam as mãos com frequência e de forma correta. No entanto, em todas as amostras observou-se a presença de mi- 
cro-organismos mesófilos aeróbios, com valores que variaram de 4,4x102 a 4,9x105UFC/mão. Indicando que, naquele momento, as mãos de todas as manipuladoras apresentavam condições higiênico-sanitárias inadequadas, uma vez que todas as amostras analisadas obtiveram crescimento acima que 102UFC/mão, parâmetro este sugerido pela Organização Pan-Americana da Saúde (OPAS, 2006).

Não há padrões ou especificações para contagens microbianas em mãos de manipuladores de alimentos, por isso procurou-se determinar faixas de contagens que pudessem servir de orientação, expressas em UFC/mão. Para mesófilos aeróbios: Faixa I - até 103UFC/mão e II - entre 103 e 104UFC/mão (ANDRADE, 2008). Dessa forma, entre as manipuladoras apenas uma $(16,6 \%)$ enquadrou-se na Faixa I, 33,3\% na Faixa II e as demais (50,0\%) apresentaram resultados superiores aos sugeridos anteriormente.

Diante dos resultados acima mencionados, observa-se que ainda existe uma dificuldade das colaboradoras em aplicar os conhecimentos adquiridos no treinamento em suas práticas diárias de trabalho, em sentido contrário ao previsto na RDC N²16 da ANVISA, que exige que todo manipulador de alimentos deve manter asseio pessoal com a finalidade de minimizar uma contaminação cruzada que pode vir a comprometer a produção de alimentos seguros e a saúde dos alunos (BRASIL, 2004).

\section{Avaliação higiênico-sanitária das superfícies dos aparelhos de bebedouro e torneiras}

A avaliação higiênico-sanitária das superfícies dos bebedouros (bocais das torneiras, sistema de abertura/fechamento), de canecas coletivas, das três torneiras da cozinha e as demais utilizadas no escovódramo (local de higienização bucal), foi realizada por meio da técnica de Swab. As Figuras 1 e 2 ilustram algumas das superfícies analisadas. 

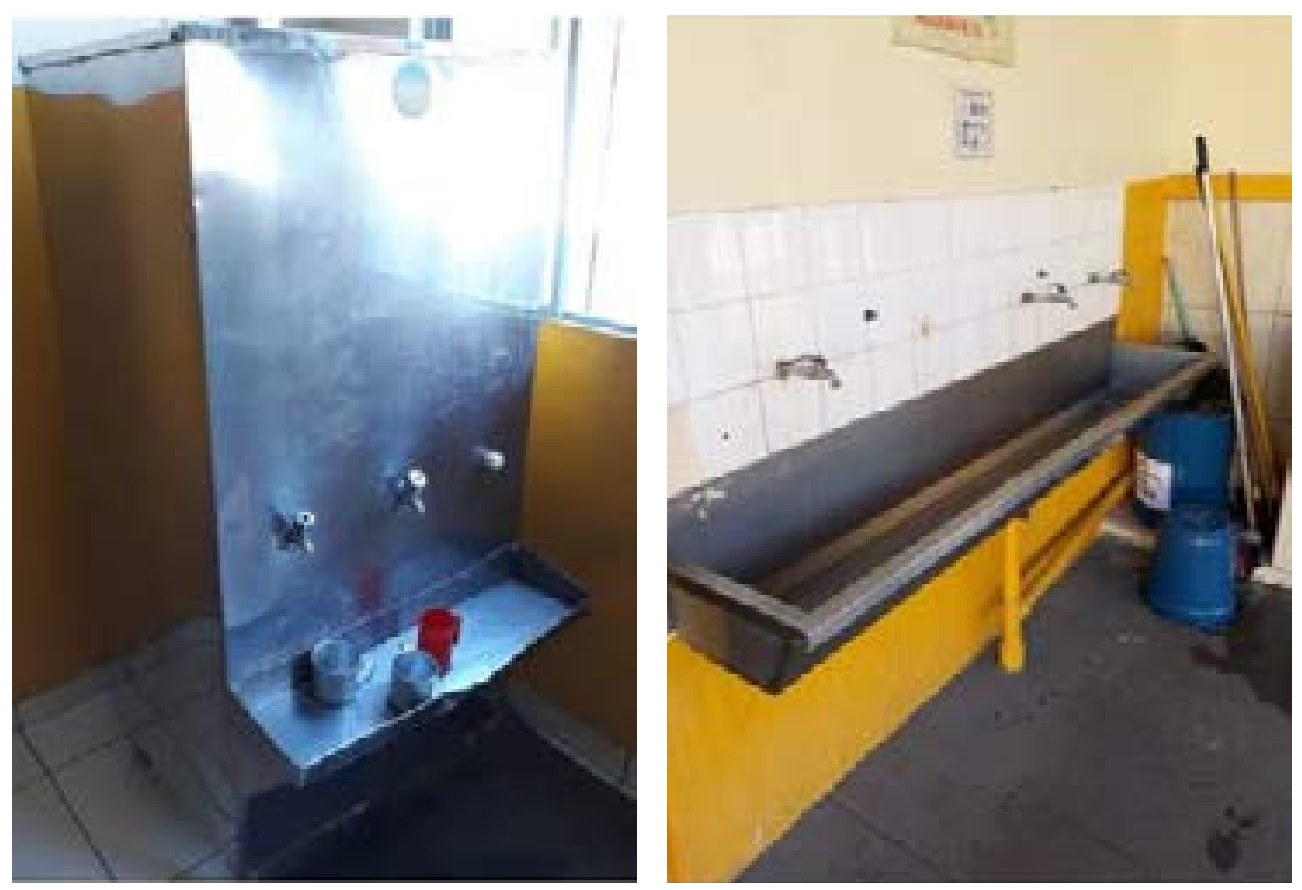

Figuras 1 e 2: Superfícies analisadas pela técnica do Swab.

Fonte: Acervo pessoal

Verificou-se que o processo de higienização dos aparelhos de bebedouros, das torneiras da cozinha e do escovódromo ainda apresenta falhas consideráveis. A análise microbiológica dos bocais dos bebedouros revelou que, das 12 amostras, todas (100\%) apresentaram resultados positivos para micro-organismos mesófilos aeróbios com um valor mínimo estimável de 2,25×104UFC/ superfície, superior a recomendações para condições higiênico-sanitárias satisfatórias de 1,2×104UFC para superfícies menores. De acordo com CARVALHO et al. (2005), a contagem padronizada por mesófilos tem sido usada como indicador de qualidade higiênica de determinados locais e, quando presente em grande número, indica falhas durante o processo de higienização.

Outro resultado importante diz respeito aos Swab das canecas que se encontravam nos bebedouros, ambas apresentaram contagem mínima estimável de 2,25×104UFC/caneca. Esses resultados indicam um cenário preocupante, visto que ocorre o compartilhamento da caneca pelos alunos e consequentemente o aumento da possibilidade de ocorrência de contaminação cruzada. 


\section{Treinamento e avaliação dos questionários}

No total, seis manipuladoras aceitaram participar do treinamento teórico de Boas Práticas de Fabricação, que trabalham em tarefas relacionadas ao preparo da merenda e higiene da escola. As figuras 3 e 4 ilustram o treinamento realizado.
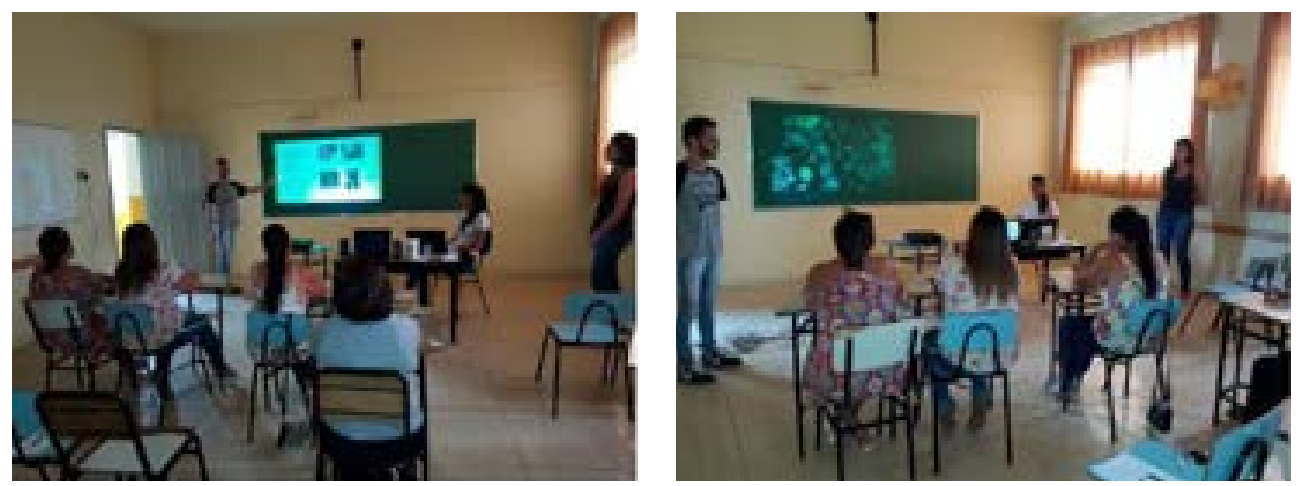

Figuras 3 e 4: Treinamento teórico de Boas Práticas de Fabricação. Fonte: Acervo pessoal

Com a aplicação do questionário nesses dois momentos: an14 tes e após o treinamento, foi possível observar que a ação realizada pelo projeto foi efetiva e trouxe resultados satisfatórios. O gráfico (Figura 5) mostra a porcentagem de acertos antes e após o treinamento teórico-prático. Não houve diferença significativa $(p>0,05)$ na porcentagem de acertos antes e após o treinamento entre nenhuma das colaboradoras.

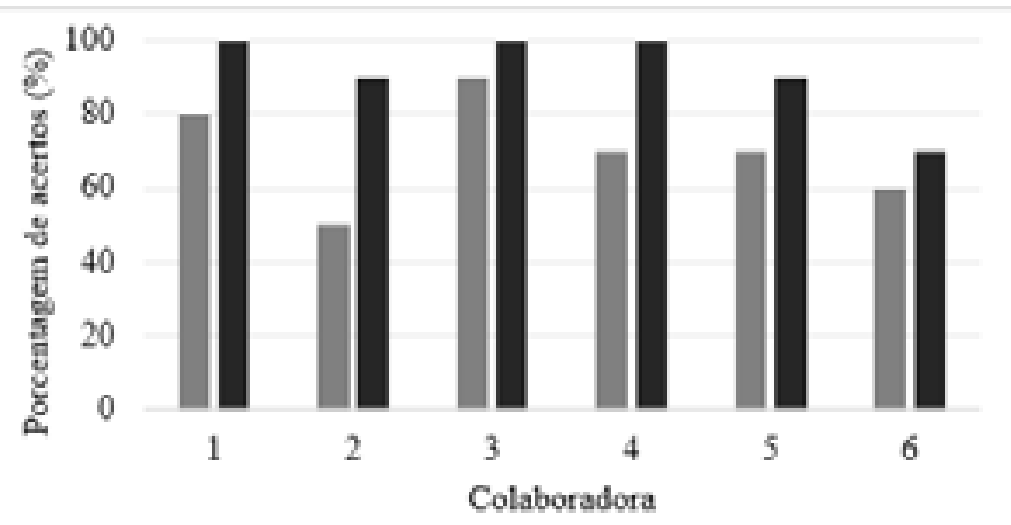

n Antes do treinamento = Após o treinamento

Figura 5: Representação gráfica da porcentagem de acertos antes e após o treinamento. Fonte: Acervo pessoal 
Ao avaliar a porcentagem de acertos de acordo com a Figura 5, é possível observar que todas as participantes apresentaram resultados consideráveis após a aplicação do treinamento, sendo que $50,0 \%$ dessas obtiveram rendimento máximo. Outro resultado que chama a atenção é o apresentado pela colaboradora 2, que obteve um aumento de $40,0 \%$ no número de acertos. Até mesmo em um cenário pouco otimista, a colaboradora 6 que obteve apenas 10,0\% de aumento no número de acertos apresentou resultado positivo. De um modo geral, foi possível observar que todas as participantes obtiveram aumento na porcentagem de acertos, que antes do treinamento apresentava média de 70,0\% e após o mesmo atingiu o resultado médio de $91,7 \%$, o que demonstra que o oferecimento de treinamento pode contribuir com o processo de higienização.

\section{5}

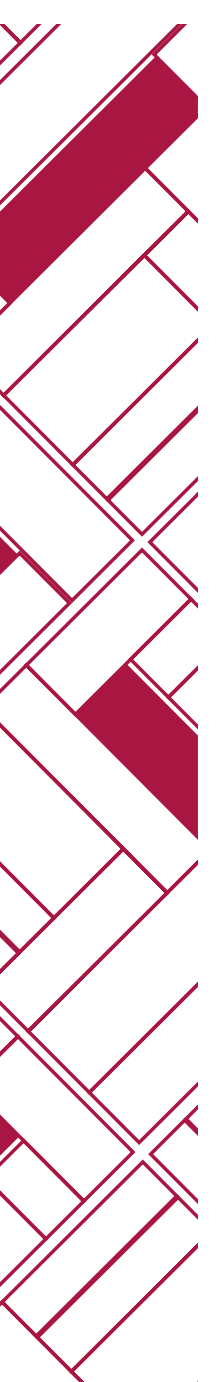

\section{Atividades de conscientização}

Foram elaboradas três cartilhas para conscientização de pais e alunos, merendeiras e professores da escola. O objetivo do material foi instruir e informar a todos. As cartilhas foram entregues entre os meses de março e abril de 2019, junto as atividades realizadas com as crianças e funcionárias da escola. As cartilhas são apresentas nas Figuras 6, 7 e 8. 
Chuá, Chuá, Água Boa Pra Tomar

Thales Del'Arcos • Milena do Nascimento Santos, et al...
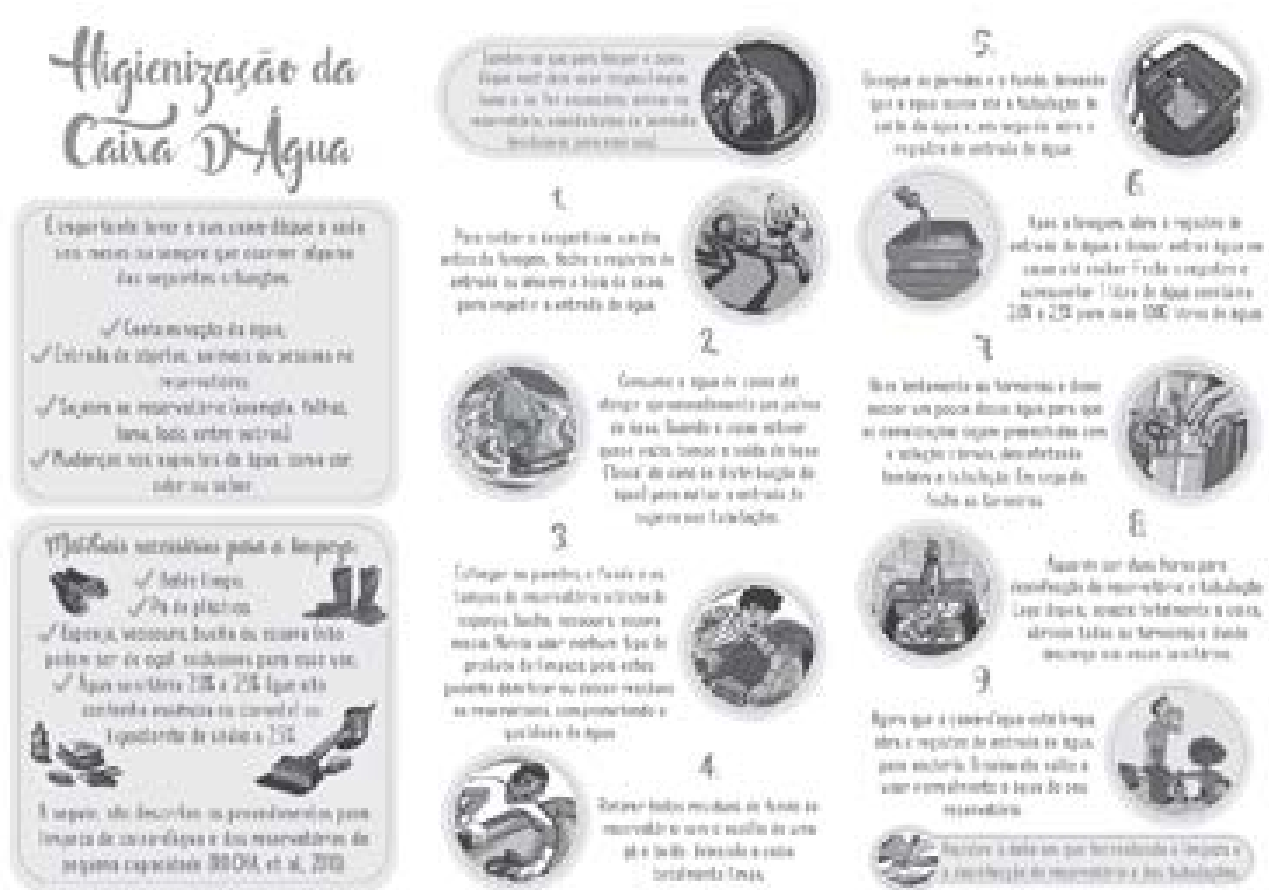

3
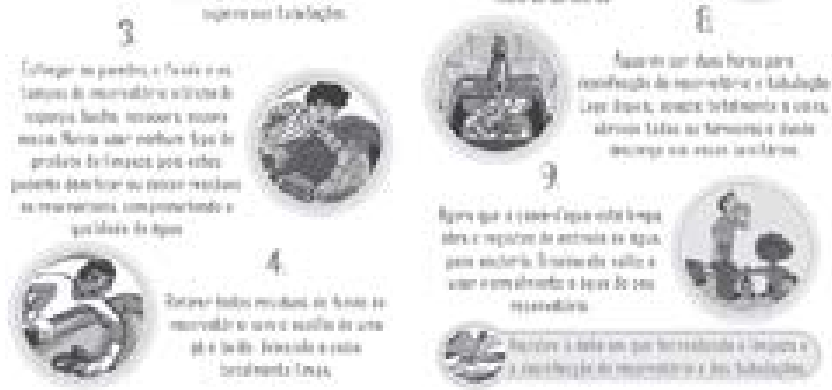

Figura 6. Cartilha educativa sobre a correta higienização das mãos. Fonte: Adaptado de ROCHA et al., 2010.

\section{6}

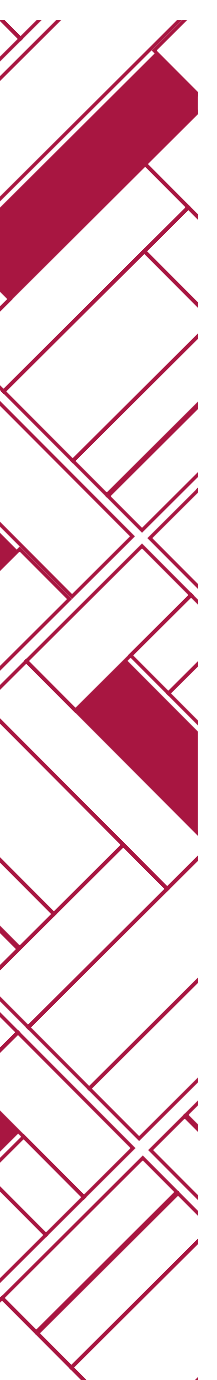

4.

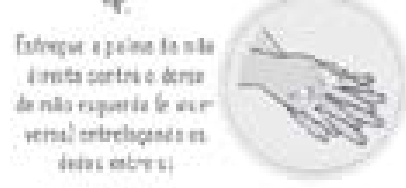

S.

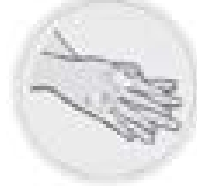

6

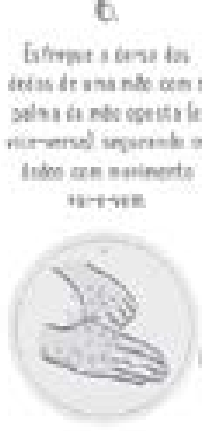

8

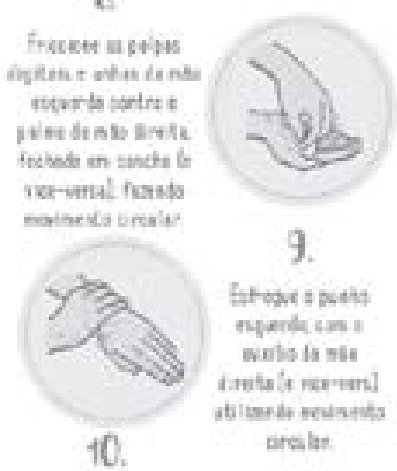

towest $\mathrm{n}$ nees

reserte wimibus in moserte forte andab swetı as nas misecins ines

terein te as waide.

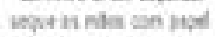
belke cenarties:

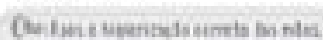

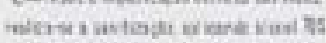

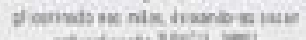
neters mete likil irel

Figura 7. Cartilha educativa sobre a correta higienização das mãos. Fonte: Adaptado de ROCHA et al., 2010. 

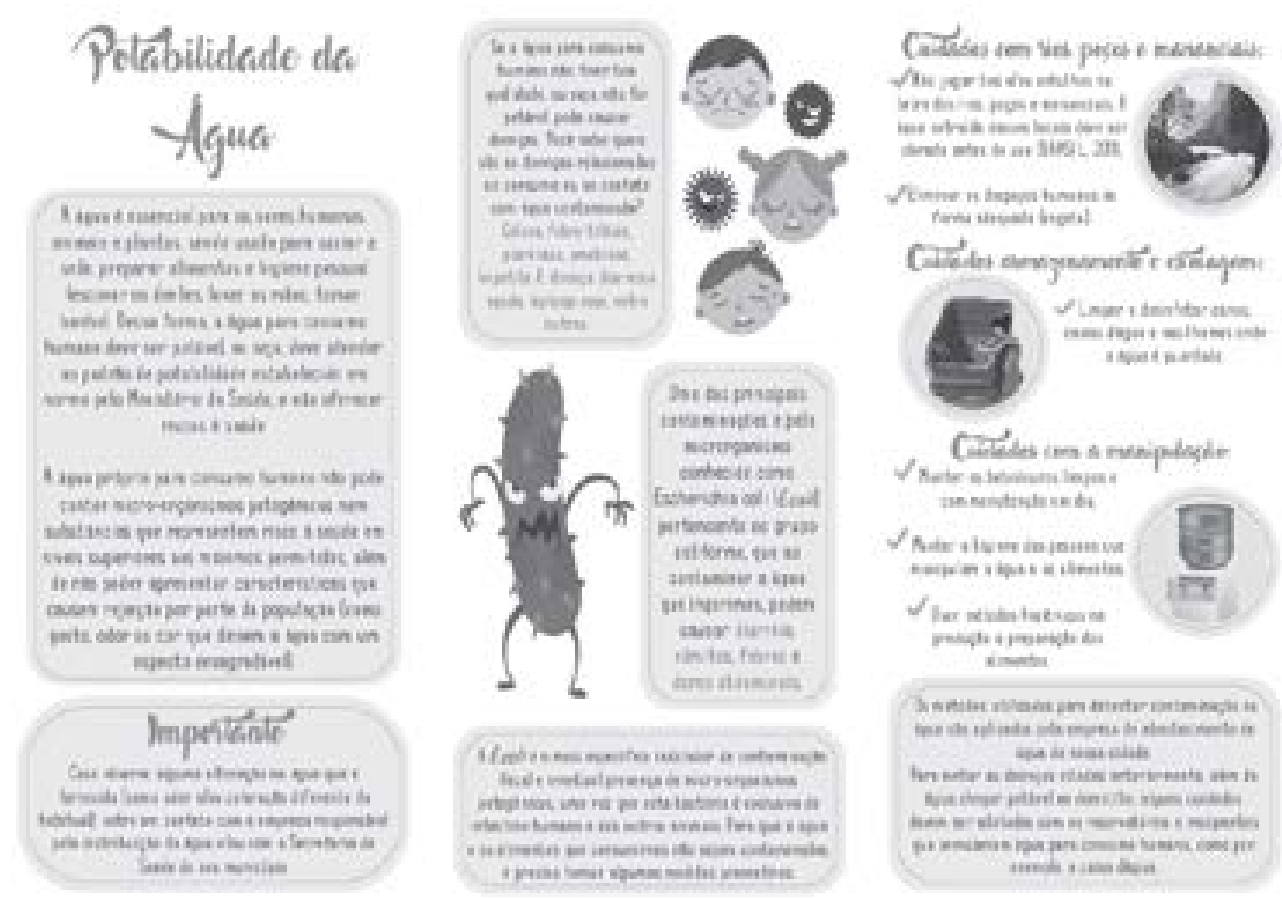

Figura 8: Cartilha educativa sobre a importância da potabilidade da água. Fonte: Adaptado de ROCHA et al., 2010.

A última etapa do projeto teve como objetivo lidar diretamente com os alunos com faixa etária compreendida entre seis e dez anos, cursando do $1^{\circ}$ ao $5^{\circ}$ do ensino fundamental em tempo integral e de baixa renda. A dinâmica do "Lava uma mão, lava a outra" foi realizada com o auxílio de tintas guache que caracterizavam a sujeira nas mãos das crianças (Figuras 9 e 10). Durante esse momento de aprendizagem lúdica, vendavam-se os alunos e pediam para que eles lavassem as mãos como de costume. Em seguida, as vendas foram retiradas e as crianças puderam observar quais foram as regiões das mãos em que elas não se atentavam em higienizar no momento de lavagem.

Ao final da gincana, os pesquisadores ensinaram aos alunos os dez passos para a correta higienização das mãos. Nesse momento, realizou-se uma discussão aberta para que todos pudessem participar, expressar seus conhecimentos e retirar dúvidas em relação a higiene pessoal especificadamente das mãos. 


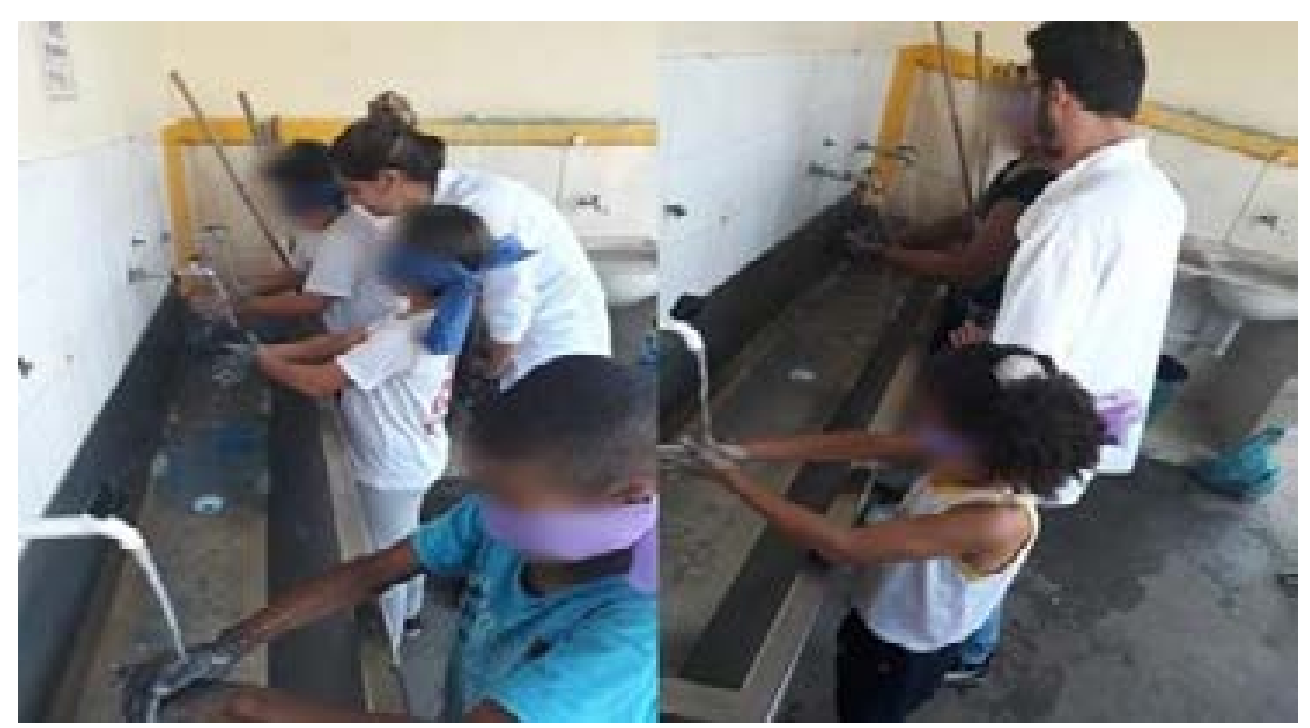

Figuras 9 e 10: Gincana lúdica com os alunos. Fonte: Acervo pessoal

\section{Conclusão}

A água de consumo da instituição apresenta-se apta para consumo humano, porém as baixas condições higiênico-sanitárias dos bebedouros, das canecas e das mãos dos manipuladores indicam a urgente necessidade de se implantar procedimentos de higiene operacional com o intuito de reduzir ou eliminar riscos associados com a contaminação que podem comprometer a saúde da comunidade acadêmica.

Do ponto de vista extensionista, o projeto obteve impacto significativo, uma vez que o conhecimento e a aplicação da higienização e a produção de alimentos seguros é fundamental para manter a saúde das crianças. O projeto apresentou-se como ferramenta eficaz de propagação e compartilhamento do conhecimento de higiene pessoal e industrial.

\section{Agradecimentos}

A FUNARBEX UFV pela concessão da bolsa, à escola por ter nos cedido o espaço e os horários para o cumprimento das atividades e as minhas amigas voluntárias do projeto. 


\section{Referências}

ANDRADE, Nélio José de. Higiene na indústria de alimentos. São Paulo: VARELA, 2008. 412P.

araújo, Tharles Mesquista; Baraúna, Alexandre Cardoso; MeneSes, Cátia Alexandra Ribeiro. Identificação de escherichia coli em ÁGua de bebeDOUROS E NOS PRóPRIOS APARELHOS DE QUATRO ESCOLAS PÚblicAS DE BOA VISTA

- Roraima - Brasil. Congresso de Pesquisa e Inovação da Rede Norte Nordeste de Educação Tecnológica (CONNEPI), 4., 2009, Belém (PA). BRASIL. Ministério da Saúde. Portaria de Consolidação Nº5, de 28 de SETEMBRO de 2017. Consolidação das nORMAS SObre AS AÇões E OS SERVIços de saúde do Sistema Único de Saúde. Diário Oficial da República Federativa do Brasil, Brasília. 2017.

19

BRASil. Ministério da Saúde. Portaria 2.914, de 12 de dezembro de 2011. Dispõe sobre os PRocedimentos de CONTROLE E VIGILÂNCIA DA QUALIDADE DA água para o consumo humano e seu padrão de potabilidade. Diário Oficial da República Federativa do Brasil, Brasília. Ministério da Saúde, 2011.

Brasil. Agência Nacional de Vigilância Sanitária. Segurança do Paciente em Serviços de Saúde: Higienização das Mãos. Diário Oficial da República Federativa do Brasil, Brasília. Anvisa, 2009. 105p.

BRASil. Ministério da Saúde. Resolução RDC N²16, de 15 de setembro de 2004. Aprova o regulamento técnico de boas práticas para Serviços de alimentação. Diário Oficial da República Federativa do Brasil, Brasília, ANVISA, 2004.

BRASil. Ministério da Agricultura, Pecuária e Abastecimento. Instrução Normativa Nº62, de 26 de agosto de 2003. Oficializa Os Métodos Analíticos Oficiais para Análises Microbiológicas para Controle de Pro- 
dutos de Origem Animal e Água. Diário Oficial da República Federativa do Brasil, Brasília. 2003.

Brasil. Ministério da Agricultura, Pecuária e Abastecimento. PortarIA N³68, de 4 de SETEMBRo de 1997. Regulamenta sobre As Condições HIGIÊNICO-SANITÁRIAS E DE BOAS PRÁTICAS DE FABRICAÇÃO PARA ESTABELECIMENTOS ELABORAdORES/INDUSTRIALIZAdORES de alimentos. DiÁRIO OFICIAL DA República Federativa do Brasil, Brasília. 1997.

CASTANIA, Janaina. Qualidade da Água utilizada para consumo em escolas públicas municipais de ensino infantil de Ribeirão Preto (SP). 2009. Dissertação (Mestrado em Enfermagem em Saúde Pública) - Escola de Enfermagem de Ribeirão Preto, Universidade de São Paulo, 2009.

FORTUNA, JORGE LUIZ. ASPECTOS HIGIÊNICO-SANITÁRIOS NO PREPARO DE CARNE BOVINA SERVIDA EM REFEIÇÕES ESCOLARES DE INSTITUIÇÕES MUNICIPAIS E ESTADUais, no estado do Rio de Janeiro. Revista Higiene Alimentar. v. 16, N. 95. 2002, Р. 23-33.

germano Pedro Manuel Leal; Germano, Maria Izabel Simões. Higiene E VIGILÂNCIA SANitáRia de Alimentos. São PAUlo: Manole; 2015. 1112p.

KOSEK, M.; BERN, C.; GUERRANT, R. L. THE MAGNITUDE OF GLOBAL BURDEN OF DIARROHOEAL DISEASE FROM STUDIES PUBLISHED 1992-2000. Bulletin of the World Health Organization, v. 81, p.197-204, 2003. manChester, Ronaldo Serafim Abreu Silva; ROdRigues, Jairo Lisboa; BOMfeti, Cleide Aparecida. Determinação da qualidade da Água de Minas na Área urbana do município de Teófilo Otoni-MG-Brasil. Revista Vozes do VALE - UFVJM, N. 3, 2013.

MÜLLER, L. R.; PARUSSOLO, L. QUALIDADE MICROBIOLÓGICA DA ÁGUA utilizada para consumo em escolas municipais de Mamborê, Paraná. SaBios: Revista de Saúde e Bıologia, v. 9, n. 1, P. 95-99, 2014. 
Organização Panamericana da Saúde; Organização Mundial da Saúde; AgênCIA Nacional de VigilânCIA SanitáRIA. Codex alimentarius: higIene dos alimentos: textos básıcos. Organização Panamericana da Saúde. Brasília: Organização Pan-Americana da Saúde. 2006.

RiBeiro, Ana Christina; ReIS, Dênio Oliveira; ROSSI, Daise Aparecida. Procedimentos de HIGIENIZAÇÃO DAS MÃOS DE MANIPULADORES, EM UMA INDÚSTRIA frigorífica. Revista Higiene Alimentar, vol. 14, N. 70, P. 52- 57, 2000. ROCHA, Elissandro Santos; Rosico, Fernando Stevanin; Silva, Fabiana Lobo; LUZ, Tereza Cecília Santos da; FORTunA, Jorge Luiz. Análise MICROBIOLÓGICA DA ÁGUA DE COZINHAS E/OU CANTINAS DAS INSTITUIÇÕES DE ENSINO do município de Teixeira de Freitas (BA). Revista Baiana de Saúde Pública V.34, N.3, P.694-705 JUL./SET. 2010.

SCuRACChiO, Paola Andressa. Qualidade da Água Utilizada para Consumo em Escolas no Município de São Carlos - SP. Dissertação (Mestrado em Alimentos e Nutrição) - Universidade Estadual Paulista “Júlıo de Mesquita Filho", Araraquara, 2010, 57p.

SilVA, Célia da; Germano, Maria Izabel Simões; Germano, Pedro

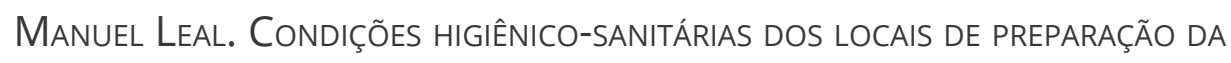
merenda escolar, da Rede estadual de ensino em São Paulo, SP. Higiene Alimentar, São PaUlo, v. 17, N. 110, P. 49-55, 2003.

SOUSA, Cristina Paiva de. Segurança alimentar e doenças veiculadas por ALIMENTOS: UTILIZAÇÃO DO GRUPO COLIFORME COMO UM DOS INDICADORES DE QUALIdade de alimento. Revista Atenção Primária À Saúde, 2006. 